\title{
Net yield efficiency: Comparing salad and vegetable waste between community supported agriculture and supermarkets in the UK
}

\author{
Nigel Baker,a Simon Popay,b James Bennett, ${ }^{*}$ and Moya Kneafsey d \\ Coventry University
}

Submitted June 13, 2018 / Revised November 28, 2018, and January 28 and January 29, 2019 /

Accepted January 29, 2019 / Published online March 22, 2019

Citation: Baker, N., Popay, S., Bennett, J., \& Kneafsey, M. (2019). Net yield efficiency: Comparing salad and vegetable waste between community supported agriculture and supermarkets in the UK. Journal of A griculture, F ood Systems, and C ommunity D evelopment,8(4), 179-192.

https:/ / doi.org/ 10.5304/ jafscd.2019.084.013

Copyright @ 2019 by the Authors. Published by the Lyson Center for Civic Agriculture and Food Systems. Open access under CC-BY license.

\begin{abstract}
Food security is high on the global agenda. Two factors make it particularly pressing: the continuing rise in the global population, and the failure to adequately feed the current one. An area that has been the focus of much recent attention has been food waste; the Food and Agriculture Organization of the United Nations (FAO) estimates that as much as a third of all food is lost or wasted. This
\end{abstract}

a Nigel Baker, D eceased, Centre for Agroecology, Water and Resilience; Ryton Gardens, Wolston Lane, Coventry, CV8 3LG, UK

b Simon Popay, Ph.D ., Student, Centre for Agroecology, Water and Resilience; Ryton Gardens, Wolston Lane, Coventry, CV8 3LG, UK; popays@ coventry.ac.uk

c* Corresponding author: James Bennett, Senior Lecturer, Environmental Science, Centre for Agroecology, Water and Resilience; Ryton Gardens, Wolston Lane, Coventry, CV8 3LG, UK; j.bennett@ coventry.ac.uk paper argues that by taking a food system approach that accounts for yields as well as loss and waste in distribution and consumption, we can compare the contribution of different food systems to food security. A novel concept of "net yield efficiency" (NYE) is introduced that accounts for this. We present an illustrative case study of the levels of fresh vegetable and salad waste in the supermarketcontrolled food system compared with a community supported agriculture (CSA) scheme. This case

d Moya Kneafsey, Professor of Food \& Local D evelopment/ Human G eography, Centre for Agroecology, Water and Resilience; Ryton Gardens, Wolston Lane, Coventry, CV8 3LG, UK; moya.kneafsey@ coventry.ac.uk

\section{Authors N ote}

This paper is based on Nigel Baker's Masters of Science thesis. Nigel had been further developing the ideas in this paper as a Ph.D. student before he passed away. His wish and that of his wife was to see his work published. 
study explores whether the CSA and its members are less wasteful than the supermarket system. The study found that when all stages of the food system were measured for waste, the CSA dramatically outperformed the supermarket system, wasting only $6.71 \%$ by weight compared to $40.7-47.7 \%$. Even accounting for difficulties in estimating waste, the findings underline the differences between these systems. On this basis, the paper argues that the NYE measure provides a more accurate picture of food system performance than current measures, which tend to focus on yield alone.

\section{Keywords}

Case Study; Community Supported Agriculture; Food Loss; Food System; Food Waste;

Supermarkets; United Kingdom; Y ield

\section{Introduction and Background}

Global food security is a high priority among food and agriculture experts and the world's governments, politicians, and media (Carrington, 2014; FIAN International, 2014). The 1996 World Food Summit defined food security as "when all people, at all times, have physical and economic access to sufficient, safe and nutritious food to meet their dietary needs and food preferences for an active and healthy life" (WFS, 1996, Plan of Action, para. 1). Looking ahead, global food demand is set to double by 2050. Y et increasing production is constrained by slowing yield growth, limited arable land, global warming, and other environmental constraints (Ray, Mueller, West, \& Foley, 2013; Tilman, Balzer, Hill, \& Befort, 2011).

Given these constraints on increased production, reducing food loss and waste (FLW) is an important step in addressing the world's food security concerns (Alexander, Brown, Arneth, Finnigan, Moran, \& Rounsevall, 2017; Smith, 2013). The FAO suggests that one-third of food produced for human consumption is lost or wasted annually (FAO, 2011). Waste is particularly high for fresh fruits and vegetables, up to a third of which never reach supermarket shelves because of (often aesthetically driven) supermarket standards (Institution of Mechanical Engineers, 2013; Porter, Reay, Bomberg, \& Higgins, 2018). Such levels of
FLW not only represent wasted resources such as land, water, and energy, but also contribute to greenhouse gas emissions.

The drivers of FLW are complex and multifaceted, with loss and waste occurring on-farm, in supply chains, and in households. Indeed, "The very extent of food losses and waste invites us to consider them not as an accident but as an integral part of food systems" (High Level Panel of Experts on Food Security and Nutrition [HLPE], 2014, p. 11). Food systems are increasingly complex and global, dominated by powerful corporate bodies motivated primarily by profit (McMichael, 2013). In this context, supply chain waste is driven by a combination of regulations, private grading standards, power differentials between farmers and retailers, and the expectations and behaviors of consumers (Porter et al., 2018). Household waste is similarly driven by a complex range of factors, including ambivalent attitudes toward waste; preferences regarding safety, taste, and freshness; age of household members; household size; and wider social, economic, and cultural structures (Schanes, D obernig, \& Gözet, 2018).

Given the complexity of food security, there is a need to re-examine the food system as a whole if food security priorities are to be achieved (Ingram, 2011). As conventionally grown food is almost all tied to the supermarket-controlled food system with high levels of FLW, this paper explores the idea that "alternative" systems, with organic production and closer producer-consumer relations, may be more efficient overall. O rganic and lowinput farming has a variety of recognized environmental benefits, including building long-term soil fertility (Rosset \& Altieri, 2017). However, an extensive meta-analysis by de Ponti, Rijk, and van Ittersum (2012) suggests that organic agriculture yields are only $80 \%$ of those achieved by conventional farming (albeit with large variation). A key question for alternative food systems, therefore, is whether efficiencies in the rest of the system can compensate for a $20 \%$ field-yield deficit.

This paper introduces the concept of $\mathrm{Net}$ Yield Efficiency (NYE) as a tool for measuring the efficiency of food systems in both producing and distributing food. Specifically, we combine data on yield with data on FLW to estimate how much 
food is actually consumed from a given farm area. We illustrate NYE by applying it to the case of Canalside, an organic CSA scheme in the UK. D ata on farm and household FLW from the Canalside CSA and its members are compared with national averages in the UK for salad and vegetables. Because of the effective absence of a supply chain in the CSA model (as consumers collect their produce from the farm), our CSA data collection focused on household waste. The findings suggest that the CSA system generates less FLW in comparison to the supermarket-led system. We then combine the FLW data with the $20 \%$ yield deficit to show that the FLW reductions in the CSA system can compensate for lower yields, leading to a more efficient system overall. Although this case study is very small, it illustrates how NYE can help develop an improved, comparative understanding of the performance of different food systems.

L oss and W aste in Food Systems Food loss and waste (FLW) has been defined as "a decrease at all stages of the food chain from harvest to consumption, in mass, of food that was originally intended for human consumption, regardless of the cause" (HLPE, 2014, p. 11). Food losses occur prior to the point of consumption, while waste occurs at the point of consumption. This definition can be widened to include potential food diverted to other purposes, such as meat production, biofuels, and other industrial needs. It can also include overconsumption and the consumption of highly processed, nutrient-deficient "empty calories."

There are fundamental conceptual problems with FLW, which we can only address briefly here. These particularly concern how waste frequently re-enters ecological processes as organic matter, replenishing the soil and re-entering production. $\mathrm{O}$-farm waste is commonly used in this way, and some supply chain and household FLW in the UK is returned to farming systems. It is also important to recognize that supply chain losses in the Waste and Resources Action Programme (WRAP) (2011) study (which we use below) include produce being sent to "an alternative market to the one intended," composted, used for energy recovery, and sent to a landfill. Although some of these channels mean that food is not completely wasted, much FLW still constitutes a real loss in terms of the land, labor, and other resources allocated to producing and distributing food that is never eaten.

Most attempts to measure FLW begin with all food grown or raised for human consumption. Tracking down such data is complex. At its most basic level, it involves knowing what is grown, how much leaves the farm, how much reaches the food processor, how much reaches the market, and how much is wasted by consumers. In measuring FLW along the food supply chain, an important consideration is to avoid including material that is genuinely inedible. Sometimes that is straightforwardcereal stalks left as stubble, for example. However, edible crops left in the field for economic, logisti$\mathrm{cal}$, and/ or retailing reasons are harder to track.

A very large proportion of primary biomass in agricultural systems does not enter the supply chain. This proportion of primary biomass makes up roughly $66 \%$ of the total energy value (Alexander et al., 2017). This consists mainly of agricultural residues in addition to unharvested crops and losses in the harvesting process. Figure 1 is a schematic demonstration of the major losses in the global post-harvest food system. It follows the transformations and losses of food as harvests move from farm to fork.

F ood L oss and W aste in the U K

The UK's Waste and Resources Action Programme (WRAP) has produced increasingly detailed and well-evidenced data throughout the UK food system, as well as standard definitions of different types of FLW (Table 1). The 2013 WRAP report, $\mathrm{H}$ ousehold F ood and D rink W aste in the U nited Kingdom 2012, is one of the most comprehensive studies of household food waste in the UK. A compositional analysis of food waste from 1,800 households was combined with waste audit data from local authorities and other studies to generate estimates of waste and its "avoidability."

Supermark et-driven supply chain and household waste Supermarket practices are arguably the biggest driver of FLW in the UK (Stuart, 2009). Supermarkets aim to sell as much food as possible, with the highest possible mark-up. Maximizing repeat 
Figure 1. Schematic of Global Post-harvest Food Loss and Waste (FLW) (kcal per capita per daya)

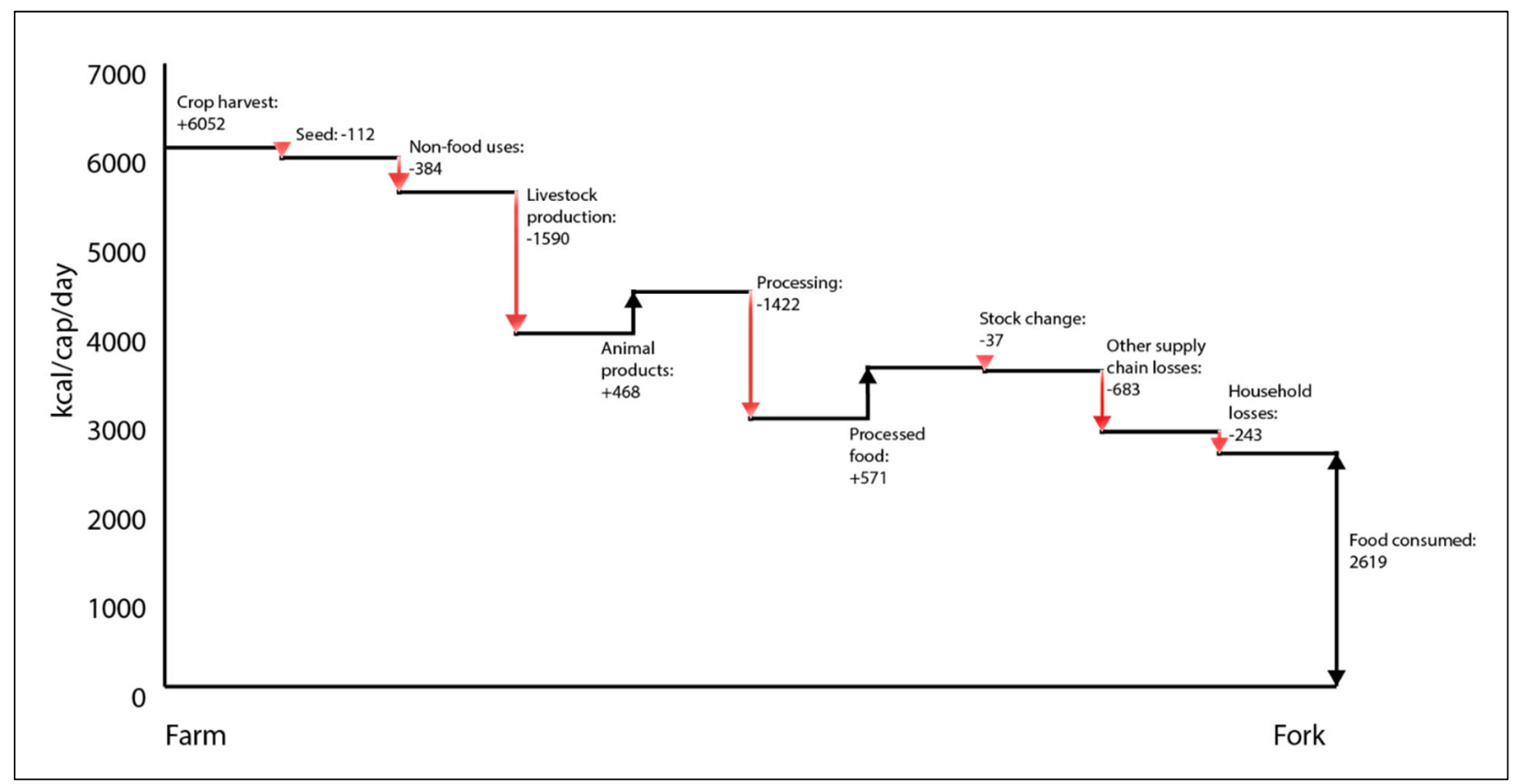

Reproduction of a diagram in Lundqvist, de Fraiture, \& Molden (2008) based on data from Alexander et al. (2017) for the year 2011. See Alexander et al. (2017) for a more detailed representation in a Sankey diagram. This diagram is based on a world population of 7 billion.

a Kilocalorie (kcal) is the British term for the U.S. Calorie.

Table 1. Definitions of Household Food Waste

\begin{tabular}{lll}
\hline Terms & Definition & Examples \\
\hline Avoidable Food Waste (AFW) & $\begin{array}{l}\text { Food and drink thrown away that was, at some } \\
\text { point prior to disposal, edible. }\end{array}$ & Bread, apples, meat \\
Possibly Avoidable Food Waste & $\begin{array}{l}\text { Food and drink that some people eat and others } \\
\text { do not or that can be eaten when a food is } \\
\text { prepared in one way but not in another }\end{array}$ & Bread crusts, potato skins \\
Unavoidable Food Waste & $\begin{array}{l}\text { Waste arising from food or drink preparation that } \\
\text { is not, and has not been, edible under normal } \\
\text { circumstances }\end{array}$ & $\begin{array}{l}\text { Meat bones, egg shells, pineapple } \\
\text { skin, tea bags }\end{array}$ \\
\hline
\end{tabular}

From Waste and Resources Action Programme [WRAP], 2009, p. 4.

business is their main goal, and in this sense it could be argued that consumer wastefulness is actually beneficial to supermarkets. Household food waste of $22 \%$ by volume (WRAP, 2009) potentially equates to $22 \%$ more sales.

The supermarket-led system is analogous to an industrial process, characterized by uniformity, standardization, and long, often complex, supply chains. Fresh fruit and vegetables in particular do not conform easily to these systems. They are not naturally uniform, standardized, or suited to a long supply chain; offer little opportunity for added value; have a short shelf life and an unpredictable supply; and less favorable produce is often rejected by consumers. These qualities mean that they are not the sort of food supermarkets prefer to sell. As noted by the HLPE (2014), "the standardization of the products offered to consumers is a major cause of food losses and waste in modern retailing systems" (p. 15). Blythman (2004) quotes one supplier saying, "supermarkets would stop selling fresh, unprocessed food entirely if they thought they 
could get away with it [. . . They stock it because they have to, because people expect it" (p. 69).

Because supermarkets must sell fresh fruit and vegetables, much ingenuity and expense have gone into ensuring that the produce is easy to manage. Packaging systems and temperature-controlled supply chains allowed Tesco (a large UK-based supermarket chain), for example, to increase the shelf life of their fresh vegetables from five days in 1987 to 11 days in 2002 (Gustafsson, Jonson, Smith, \& Sparks, 2009). While such processes ought to reduce FLW, the restrictions on size and shape that come with them do not. Meeting supermarket quality standards is consistently reported as the dominant factor in supply chain waste in the UK. For example, supermarkets will reject tomatoes for a 5\% size variation, light scarring or blemishing, imperfect shape, and variation in color or ripeness (Blythman, 2004). Although EU standards have been cited in the popular press as drivers of this type of waste, UK supermarket standards tend to far exceed these (WRAP, 2011).

Even the most technologically aware grower cannot produce near identical vegetables. Nonetheless, the complete control that supermarkets have over growers enables them to impose severe contractual terms. This includes making growers responsible for meeting "quality" standards and "take-back" clauses that allow retailers to return produce to suppliers. Thus, in order to attempt to meet supermarket demands, the first thing a grower will do is to overproduce. As noted in
WRAP (2011), "no supplier wishes to be 'short' and will trade off delivery to their customers 'in full' (as well as on time) for high levels of field waste" (p. 36). According to one National Farmers Union (NFU) official, planting 140\% of the contracted amount is "not an unstandard example of the industry being inefficient to avoid shortfall" (Stuart, 2009, p. 109).

Table 2 illustrates data from a 2009 study of fruit and vegetable supply chain waste in the UK. While total supply chain waste varies considerably by crop (15-42\%), the waste that results from grading - largely a matter of supermarket standards - is consistently a high proportion (50$80 \%$ ) of that amount. The levels of fruit and vegetable supply chain losses provided here are also comparable with a Europe-wide figure of 33\% (FAO, 2011).

In response to the supermarket-driven standardization of produce, over the last 30 years consumers have come to expect and then demand the same set of criteria. This expectation of perfection means that consumers have little tolerance once fruit and vegetables begin to lose their superficial luster after purchasing. Consumers are also extremely unlikely to purchase "substandard"looking vegetables from other sources, making such produce unmarketable. Supermarkets also encourage excess purchasing through special offers. To a limited extent, this can help move seasonal gluts, although there is little relationship between special offers and the seasons. Smaller

Table 2. Examples of Losses in the UK Fruit and Vegetable Supply Chain (S/C)

\begin{tabular}{lccccccc}
\hline Product & Field losses & Initial grading & Storage & $\begin{array}{c}\text { Grading at } \\
\text { packing stage }\end{array}$ & Retail & $\begin{array}{c}\text { Average S/C } \\
\text { losses }\end{array}$ & $\begin{array}{c}\text { Average } \% \\
\text { loss due to } \\
\text { grading }\end{array}$ \\
\hline Onion & $3-5 \%$ & $9-20 \%$ & $3-10 \%$ & $2-3 \%$ & $0.5-1 \%$ & $28.3 \%$ & $61.0 \%$ \\
Potato & $1-2 \%$ & $3-13 \%$ & $3-5 \%$ & $20-25 \%$ & $1.5-3 \%$ & $38.3 \%$ & $79.7 \%$ \\
Apple & $5-25 \%$ & $5-25 \%$ & $3-4 \%$ & $3-8 \%$ & $2-3 \%$ & $41.5 \%$ & $49.4 \%$ \\
Broccoli & $3 \%$ & $10 \% \mathrm{a}$ & $0 \%$ & $0 \%$ & $1.5-3 \%$ & $15.3 \%$ & $65.6 \%$ \\
Average & $5.9 \%$ & $11.9 \%$ & $3.5 \%$ & $7.6 \%$ & $1.9 \%$ & $30.8 \%$ & $63.3 \%$ \\
\hline
\end{tabular}

Adapted from WRAP (2011, p. 72) using UK-grown fresh fruit and vegetables where all supply chain figures were available. Averages (in bold) are the authors' calculations. These are based on simple averages that do not take into account the relative quantities produced. Where a range of figures is given, the midpoint was taken.

a WRAP data give field losses for broccoli as $10 \%$, and initial grading as 3\%, but they note that "grading is primarily done at picking; hence, there is a high proportion of field waste" $(2011$, p. 55). We have taken a high proportion as $70 \%$ and therefore re-allocated seven percentage points from field losses to initial grading. 
households, who usually waste a higher proportion of the food they buy (Brook Lyndhurst, 2007; Parfitt, Barthel, \& MacNaughton, 2010) are caught in the dilemma of "missing out" on such special offers. With perishables, in particular, special offers can lead to considerable FLW.

Another issue linking supermarkets to consumer behavior is the use of food labeling. O nly about half of consumers understand the meanings of "best before" and "use by" labels (Brook Lyndhurst, 2011). Another study suggests that 34\% of consumers "attributed food waste to food going past the date on the label and $21 \%$ will not take a risk with a product close to its date, even if it appears fine" (Brook Lyndhurst, 2007, p. 15). Supermarkets are naturally risk-averse. Consequently, the safety margin on much date labeling is often overly cautious and difficult to justify in consumer protection terms (HLPE, 2014). D espite not being legally required, "best before" date labels are frequently appended to packaged fruit and vegetables (Stuart, 2009). However, some supermarkets in the UK have recently begun to change how they date and sell fresh produce (BBC News, 2018).

Community Supported A griculture (C SA )

CSA is a partnership between farmers and the local community, providing mutual benefits and reconnecting people to the land where their food is grown (Community Supported Agriculture, 2018). CSAs exist in many forms, but their basis is that there is an element of risk-sharing between producer and consumer, as well as direct connectivity between consumers and how and where their food is grown. They are primarily products of postindustrial societies, reflecting consumer and producer dissatisfaction with the dominant food paradigm under which they are disconnected from the land and from each other. CSA members typically commit to paying for a share of the harvest over a long period of time, rather than purchasing specific items of produce. For farmers and growers, CSAs can offer greater financial security because of the commitment given by CSA members. Sharing the financial risks of crop failure with the community (as well as the bonuses of bountiful harvests) also provides a degree of financial security. In addition, CSAs offer farmers an escape from the vagaries of the supermarket supply chain and very often the chance to farm without damaging the sustainability of the soil and the environment. For consumers, being a CSA member is about reconnecting with food, knowing where it comes from, how it was grown, and that it is healthy and usually organic.

In 2011, the number of CSAs in England stood at 80, providing fresh food (primarily vegetable and salad crops) to 5,000 households. Their total area is around 3,200 acres (1,295 hectares), and annual sales are $£ 7$ million (about US $\$ 9$ million) (Saltmarsh, Meldrum, \& Longhurst, 2011).

The relationship in a CSA between the consumer and the producer, as well as between the crop and the land, is entirely different to that between a supermarket shopper and the source of his or her basket of goods (Kneafsey, Cox, Holloway, D owler, Venn, \& Tuomainen, 2008). In terms of overall FLW, what is potentially most significant is the absence of a complex, retailer-dictated supply chain. In essence, there is no supply chain for a $\mathrm{CSA}$; there are only the producer(s) and the consumers. There remain certain points in the CSA system where waste is possible- specifically in regard to the harvesting process, storage, and what is not collected by CSA members. The absence of a formal grading process seems to be the CSA's main advantage in reducing supply chain waste. Any waste that does arise is generated on the farm itself, and it can directly re-enter the ecosystem through composting (as with on-farm losses in the supermarket system). The lack of a complex supply chain may also help to explain why CSAs can supply food at a lower cost to consumers, especially for organic food (Cooley \& Lass, 1998; Pinkerton \& Hopkins, 2009).

The direct relationship between producer and consumer entails an effective absence of supplychain waste. What is less clear is whether and how participation in a CSA affects household waste. While supermarkets drive FLW through all the mechanisms discussed above, CSAs also have the potential to encourage FLW, for example, by giving consumers less choice over what they receive. This study, therefore, focuses on whether CSA members are less wasteful than typical supermarket shoppers, leading to a more efficient system overall. 


\section{Methodology}

The C oncept of $\mathrm{N}$ et $\mathrm{Y}$ ield $\mathrm{E}$ fficiency

This paper proposes Net Yield Efficiency (NYE) as an important indicator of the efficiency of food systems. NYE is a measure of the yield actually consumed - not simply what is grown. In other words, it combines farm productivity data with FLW data to arrive at a figure that describes a food system's effectiveness at producing food and delivering it to the fork.

NYE=yield - supply chain waste- household waste

\section{Canalside}

Canalside Community Food is an organic CSA scheme situated just outside Leamington Spa in Warwickshire, UK. Launched in 2007, the scheme provides vegetable shares for around 150 households, all year round. Canalside grows all the produce that goes into their vegetable shares; that is, they do not purchase produce to supplement their harvest. Table 3 shows approximate yield data for selected crops produced organically at Canalside, which uses intensive and protective cropping. The produce is overwhelmingly seasonal, supplemented by produce that can be stored (usually root vegetables). Inevitably, the amount and type of produce vary significantly throughout the year. At seasonal peaks, members receive large quantities of certain vegetables, and it is common for members to give surplus produce to friends and family. Members also understand that there are times when the size of the share will be relatively small.

Table 3. Estimated Yields Produced per Crop at Canalside CSA

\begin{tabular}{cccc}
\hline Crop & Planted area $\left(\mathrm{m}^{2}\right)$ & Total yield & Equivalent per hectare \\
\hline Squash & 840 & $3000 \mathrm{~kg}$ & 36 tons \\
Beetroot & 580 & $2500 \mathrm{~kg}$ & 43 tons \\
Celeriac & 360 & $600 \mathrm{~kg}$ & 17 tons \\
Carrot & 1000 & $3600 \mathrm{~kg}$ & 36 tons \\
\hline
\end{tabular}

Estimated yields of selected produce by Canalside CSA using intensive and protective cropping. Source: Canalside CSA, 2013.
Members collect their shares directly from the farm, selecting, weighing and bagging up their own vegetables according to the size of their share (small, medium, or large). The very act of handling and weighing out the produce enhances the sense of connection. Most produce is picked on the day it is collected; however, produce in winter and spring often includes a significant amount of stored late-autumn harvest.

This study gathered household vegetable and salad waste data from 28 of Canalside CSA's 150 members (18.7\%) in June and July 2014. We used this data to estimate levels of avoidable food waste (AFW) that could be compared with the UK-wide WRAP data for vegetable and salad FLW. ${ }^{1}$ Although conducted on a smaller scale and at a different time of year, the methodological approach to measuring waste in our study is sufficiently similar to the WRAP study to make valid and illustrative comparisons.

Calculating CSA H ousehold FLW and Comparable W RA P Figures

Data were collected across two groups. The first group (15 participants) received kitchen caddies and were asked to collect any waste from their CSA shares over a period of two weeks. Participants were not asked to self-sort the waste and instead returned the caddies at the end of each week for waste to be weighed and analyzed (by Baker). After the second week, the caddies were redistributed to the second group (13 participants), and the process was repeated. A brief exit interview conducted after the food waste collection was complete collected data on household size, whether they consumed fresh vegetables from other sources (besides the CSA), consumption preferences (vegetarian or not), and whether they thought participating in the CSA affected their levels of household waste. D ata from the two groups were combined and treated as a single sample. This approach kept costs low and allowed more participants to be included.

${ }^{1}$ WRAP FLW data were collected in September-November 2007 for WRAP (2009) and April 2013 for WRAP (2013). 
Canalside CSA shares are typically allocated by the weight of each type of produce. This means that when members arrive to collect their produce, they are told, for example, that they are entitled to $1 \mathrm{~kg}$ (2.2 lbs.) of potatoes. We took these allocated weights as the basis for each participant's actual shares (rather than weighing each participant's share as they collected it). O ccasionally, the share would include "one or two of" an item. This was the case with cucumbers, fennel, and calabrese during the study. For these crops, average-sized examples were weighed to give a fair weight-value.

To ensure comparability with the WRAP data on AFW, inedible portions of both the share and the returned waste were removed from the calculations. The share was considered $80 \%$ edible. This figure was reached by preparing a sample medium share over four weeks and crossreferencing it against the Ministry of D efence (2014) guidelines for conversion factors of purchase weights to edible weights of produce. Edible waste was distinguished from inedible waste through a direct examination of the returned waste. Potentially avoidable waste and potentially inedible elements of the share (e.g., root vegetable skins) were excluded from the calculations to ensure a comparable estimate of AFW. The combined weight of edible vegetable and salad waste was compared to the weight of the edible share to calculate the rate of household waste.

For comparison with the household WRAP data, adjustments were needed to reflect the different types and quantities of fresh vegetables and salads between the WRAP study and this study. This meant using disaggregated figures of salad waste and vegetable waste from WRAP (2009) and combining them in accordance with the proportion of salads and vegetables in the CSA share (which had a higher proportion of salad than the WRAP study). ${ }^{2}$ Unfortunately, disaggregated data were not published in the WRAP (2013) study, so we could not make the same adjustment. As such, we have presented below (Table 4) both the unadjusted figure for the 2013 study (21\%, Figure 2) and our adjusted figure for the 2009 study (30.3\%).

Calculating CSA 0 n-farm W aste

The Canalside food chain is very simple, comprising on-farm waste and household waste only. Using the HLPE (2014) definition of FLW cited above, the on-farm FLW comprises unharvested edible crops, storage losses, and harvested crop (excluding very poor quality pest-damaged and undersized produce) not distributed to members. This study was unable to collect data on unharvested edible crops and storage losses, although they are assumed to be low. In general, the only produce that does not reach the consumer is the lowest quality, small, or badly damaged produce, storage losses, and occasionally perishable leafy vegetables at times of peak supply.

At Canalside, if there is a surplus of produce, it is made available to members as extras. When not all extras are taken, they become waste and are composted on-site (we classified these as on-farm waste). The extras will occasionally include lower quality or undersized vegetables, which in a supermarket-led system would not reach the retailer. D uring the four-week study period, the researchers recorded the total harvest (for all shares) and weighed and recorded the on-farm waste (i.e., extras which were not taken by any CSA members). In-field losses (e.g., unharvested produce or produce damaged in harvest) were not recorded. D espite the very low quality of the untaken extras, their composition was analyzed and found to have a lower proportion of inedible waste than the household shares. ${ }^{3}$ Ninety percent of the on-farm waste was found to be edible and, thus, avoidable.

\section{Results and Discussion}

A voidable $\mathrm{F}$ ood $\mathrm{W}$ aste in $\mathrm{C}$ analside Participants were predominantly two-adult households, four of which had children; four participants

\footnotetext{
2 The adjusted figure is derived from the rate of vegetable waste (19.1\%) and the rate of salad waste (45.4\%) in WRAP (2009) and the average relative amounts of vegetables (57.4\%) and salad (42.5\%) in the CSA shares. The unadjusted figure in WRAP (2009) is 20.7\%. This figure is very similar to the one in WRAP (2013).

3 This was due to waste mainly coming from entirely edible salad produce.
} 
Journal of Agriculture, Food Systems, and Community D evelopment ISSN: 2152-0801 online

https:/ / www.foodsystemsjournal.org

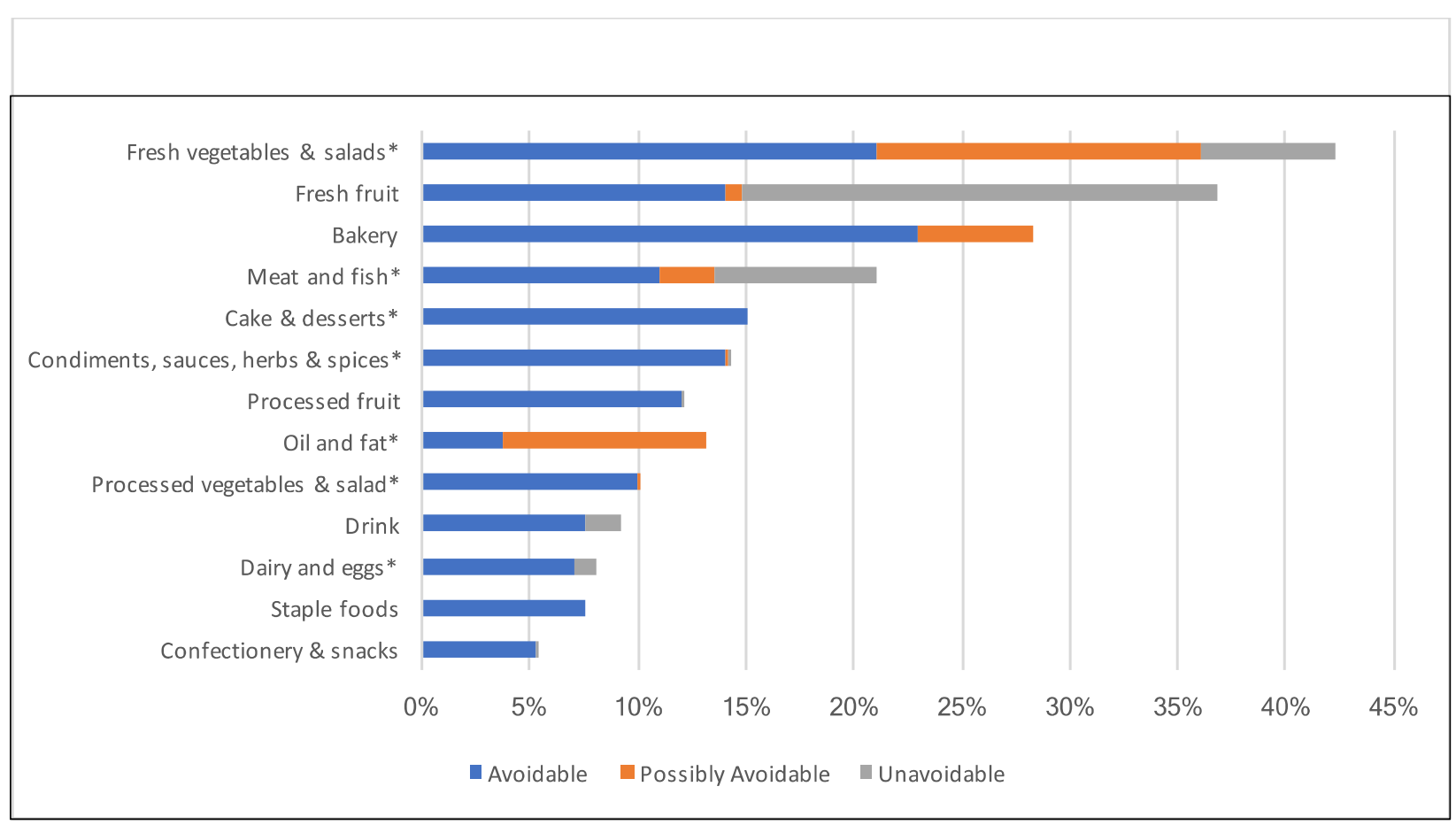

* Indicates relatively low confidence in the \% estimate, mainly due to food changing category between purchase and disposal. Note that for fresh vegetables and salads, the $\%$ is considered an underestimate.

Source: Waste and Resources Action Programme [WRAP], (2014).

were single-adult households. O nly two households reported being vegetarian or vegan. The average household avoidable food waste (AFW) for Canalside members by weight was $6.1 \%$. This is more than threefold lower than the unadjusted WRAP (2013) figure of $21 \%$, and almost five times lower than the adjusted WRAP (2009) figure of 30.3\%. Although this result must be treated cautiously (for reasons discussed below), it is a substantial difference. Individual participants' waste did vary considerably, with AFW values ranging from $0.4 \%$ to $16.6 \%$ of the edible share (Figure 3). There was no clear pattern across the different share sizes (15 households were receiving a medium share, $12 \mathrm{a}$ small share, and one a large share). The average total household waste (including all avoidable, potentially avoidable, and unavoidable waste) from the Canalside CSA share was still only $19.1 \%$.

At the same time, on-farm AFW accounted for only $0.65 \%$ of the edible harvest. Total onfarm waste over the four-week period was $11.7 \mathrm{~kg}$ (25.8 lbs.), $10.5 \mathrm{~kg}$ (23.1 lbs.) of which was considered edible. Total production was just over two tons $(4,409 \mathrm{lbs}$.), of which $1,610 \mathrm{~kg}(3,550$ lbs.) were considered edible. The extremely low figure of on-farm waste reflects the very limited grading that takes place before the food reaches the consumer. These results are summarized in Table 4.

As a food system, we estimate food loss and waste (FLW) in the supermarket-led system as being between $40.7 \%$ and $47.7 \%$, compared to only $6.71 \%$ for Canalside. Levels of both supply-chain and household FLW are much lower for the CSA than for the supermarket-led system.

\section{NYE in Canalside}

Net Yield Efficiency (NYE) aims to reflect that food production and consumption do not exist in isolation of each other; they are part of interlinked processes within a food system. The question that this research posed was: Allowing for yield differences between conventional and organic production methods, could an alternative food system (such as a CSA) still outperform the supermarket food system in terms of yield by taking food losses into account? The evidence displayed in Table 5 suggests that this is so. Organic food systems, on 
Figure 3. Canalside Members' Avoidable Food Waste (AFW) by Household

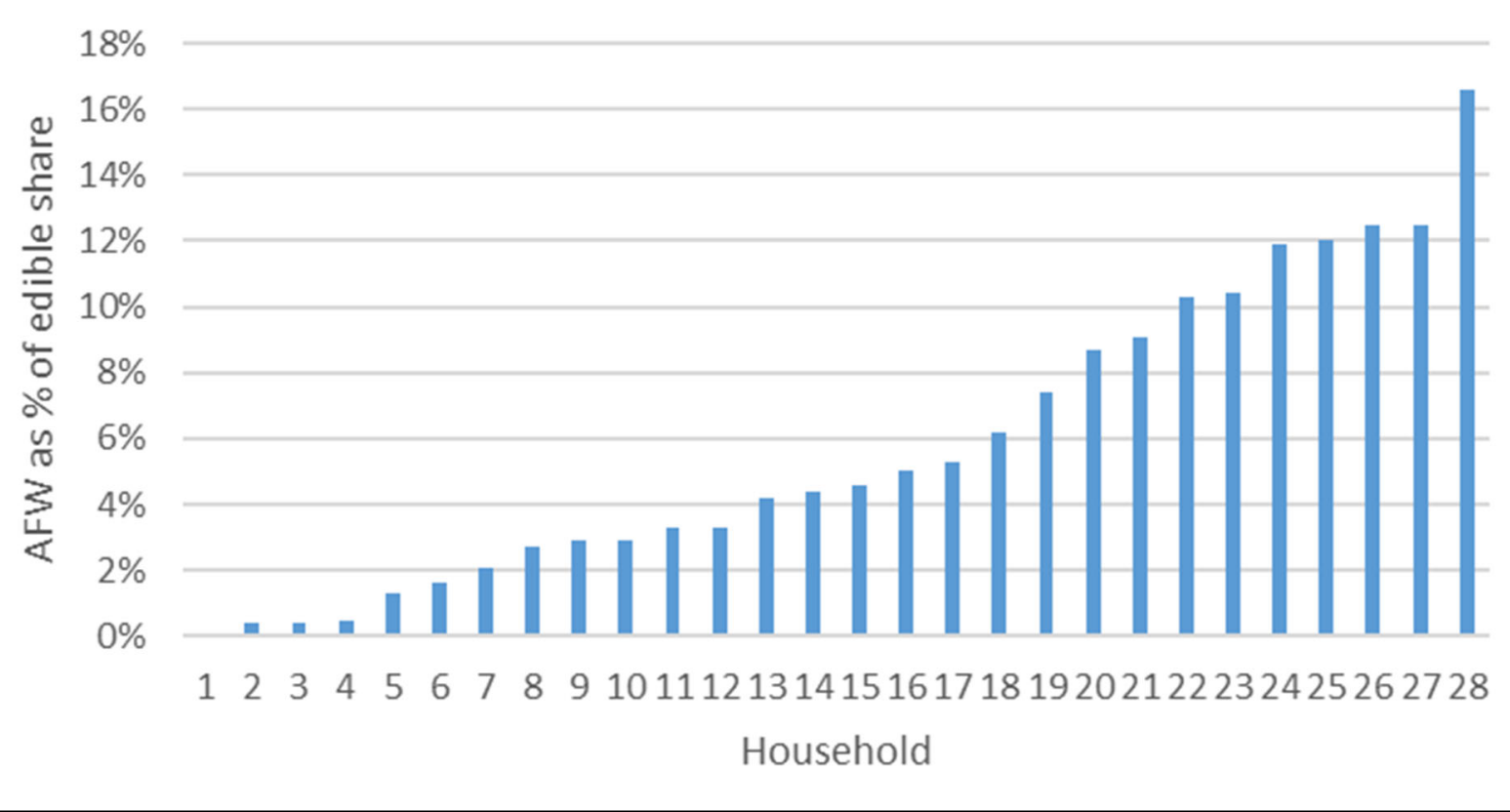

average, produce a field yield of only $80 \%$ of that of conventional systems (Ponti et al., 2012). However, the supply chain and household waste in the CSA system are substantially lower than that in the supermarket system. The lower level of FLW in the CSA system more than offsets the yield deficit. This suggests that from the same (hypothetical) hectare, the CSA system (exemplified by the Canalside CSA) is substantially more efficient than conventional farming and the supermarket food system overall.

Another way to express the data in Table 5 is to say that, given the levels of waste in the two systems, the conventional (supermarket) yield must be between 1.57 and 1.78 times that of the organic (CSA) yield for the NYEs to be equal. This is well beyond de Ponti et al.'s (2012) yield difference of 1.25 .
Table 4. Complete Food Chain Comparison of Food Loss and Waste (FLW)

\begin{tabular}{lccc}
\hline Food system & $\begin{array}{c}\text { Supply chain FLW } \\
\text { (\% of food grown) }\end{array}$ & $\begin{array}{c}\text { Household AFW } \\
\text { (\% of purchased food) }\end{array}$ & $\begin{array}{c}\text { Total food chain FLW } \\
\text { (\% of food grown) }\end{array}$ \\
\hline Canalside CSA & $0.65 \%$ & $6.1 \%$ & $6.71 \%$ \\
$\begin{array}{l}\text { Supermarket (WRAP 2013) } \\
\begin{array}{l}\text { Supermarket (adjusted } \\
\text { WRAP 2009)c }\end{array}\end{array}$ & $24.9 \%$ b & $21 \%$ & $40.7 \%$ \\
\hline
\end{tabular}

b Total food chain FLW is cumulative, rather than the simple addition of supply chain and household FLW. For example, Canalside CSA total FLW was calculated as $0.0065+(1-0.0065) * 0.061=0.0671$.

c This figure excludes in-field losses $(5.8 \%$, see table 2$)$, as no comparable figures were gathered for the CSA. In Table 5, field losses are estimated at 5\% for both food systems.

d See methodology section. 
Journal of Agriculture, Food Systems, and Community Development

ISSN: 2152-0801 online

https:/ / www.foodsystemsjournal.org

Table 5. Community Supported Agriculture (Canalside CSA) and Supermarket Net Yield Efficiency (NYE)

\begin{tabular}{|c|c|c|c|c|c|c|c|}
\hline \multirow{2}{*}{$\frac{\text { Farm type }}{\text { CSA (Canalside data) }}$} & \multirow{2}{*}{$\begin{array}{c}\begin{array}{c}\text { Hypothetical } \\
\text { field yield } \\
\text { (tons/hectare)a }\end{array} \\
8\end{array}$} & \multicolumn{2}{|c|}{$\begin{array}{l}\text { Field losses (\%) and } \\
\text { crop left ( } t / \text { ha) }\end{array}$} & \multicolumn{2}{|c|}{$\begin{array}{l}\text { Supply chain losses (\%) and } \\
\text { food remaining ( } t / \text { ha) }\end{array}$} & \multirow{2}{*}{$\begin{array}{r}\begin{array}{c}\text { Consumer } \\
\text { AFW (\%) }\end{array} \\
6.1 \%\end{array}$} & \multirow{2}{*}{$\begin{array}{r}\text { NYE } \\
(\mathrm{t} / \mathrm{ha}) \\
7.09\end{array}$} \\
\hline & & $5 \%$ & 7.6 & $0.65 \%$ & 7.55 & & \\
\hline $\begin{array}{l}\text { Supermarket (WRAP } \\
2013 \text { ) }\end{array}$ & 10 & $5 \%$ & 9.5 & $24.9 \%$ & 7.13 & $21.0 \%$ & 5.63 \\
\hline $\begin{array}{l}\text { Supermarket (adjusted } \\
\text { WRAP 2009) }\end{array}$ & 10 & $5 \%$ & 9.5 & $24.9 \%$ & 7.13 & $30.3 \%$ & 4.97 \\
\hline
\end{tabular}

a The hypothetical field yield (metric tons/hectare) is not meant to represent actual yields for any crop, but to represent that organic yields are on average $80 \%$ of those on conventional farms, as reported by de Ponti et al. (2012).

single case study with a small number of participants, we can only illustrate the application of the NYE approach rather than make claims about the wider applicability of the findings. Generally speaking, estimates have been used both from the CSA data and in the form of extrapolations from the WRAP study, which make a number of assumptions. In particular, the estimates of supply chain losses in the supermarket system (WRAP, 2011) are based on interviews with suppliers rather than a systematic collection of quantitative data along supply chains. We have also simplified the WRAP data ranges to simple averages. For the CSA data, we are confident that, in most cases, estimates are cautious and over-, rather than underestimate AFW. Nonetheless, we collected data from a small sample of self-selected CSA members, which may not be representative of the entire membership. Although the WRAP study was intended to be representative of England and Wales, it is based on the collection of waste over just one week. The CSA study presented here covered two weeks of waste (for each study group). Waste levels are likely to be highly dependent on the varieties and quantities produced, particularly for the CSA, where members have little choice in what they receive. While the WRAP data was seasonally adjusted, the CSA data was not.

Although the Canalside CSA operates in a very similar way to other CSAs, and so might be considered typical, the data here is not representative of all CSAs. Some CSAs operate more like "boxschemes," involving partial supply chains where the produce from multiple farms is distributed with varying degrees of directness to the end consumer.
Furthermore, the CSA is a specific form of a food system, and not all organic production systems have associated short supply chains. O ther systems may create more distance between the producer and the consumer, creating the possibility of additional FLW.

As far as we are aware, no other study has been conducted with the same methodology. Studying additional CSAs would have been beneficial but was beyond the practical resources available. Nevertheless, there is reason to believe that the WRAP data on AFW is robust and suitable to be used for comparative purposes.

Clearly, attributing any causal effect of supermarket-led and CSA food systems on household waste is problematic. The behavior and attitude of study participants cannot be solely attributed to their membership in Canalside. Those joining a CSA (and, further, those choosing to participate in this study) likely have an above-average understanding of food and environmental issues, including food waste. However, participation in the CSA appears to have reinforced any self-selecting predisposition. The exit interview revealed that $85 \%$ of participants thought that being part of Canalside positively influenced their attitude toward waste, with just over half suggesting it was a major influence. This echoes the findings of a study of another CSA: "Over the duration of their involvement they had become increasingly enrolled into, and motivated by, the wider value system in which the CSA is situated" (Kneafsey et al., 2008, p. 64). The exit interview also identified that most households bought fresh vegetables from other sources (ranging from 0\% to 100\% more than what 
they received from the CSA) over the study period. Although we did not look at the waste arising from this, it would be interesting to look at how different sources of produce affect household waste practices.

From discussions with participants, it was clear that being a member of Canalside increased the amount and range of produce they consumed. Due to advice from Canalside staff and conversations with others, they were also eating more parts of the produce- which would come under WRAP's definition of potentially avoidable food waste. Because the produce was organic, members knew that if they washed off the dirt, root vegetables did not need to be peeled (although some members still did so), while parts like brassica leaves and stalks were eaten by many. As all harvested edible produce was made available either within their share or from the extras box, Canalside members were eating a large amount of produce that would not have been acceptable according to supermarket standards. It would be interesting, as part of a further study, to estimate just how much of that produce would meet the "cosmetic" standards required by supermarkets.

\section{Conclusions}

This small study, looking at one local food scheme feeding 150 families, gives a glimpse of a way of producing and distributing food that minimizes associated food loss and waste (FLW). The tiny amount of waste on the supply side at the Canalside CSA demonstrates how much of an impact standards concerning edibility and marketability can have on FLW in the mainstream supply chain. Food losses on the farm are of no benefit to the farmer. For the most part, they represent a real financial loss. The only beneficiaries of FLW are supermarkets. Similarly, consumer AFW in the UK costs the average household $£ 470$ (about US\$608) annually. This figure represents a considerable amount of extra sales for supermarkets: 19\% extra sales by weight and $14 \%$ by value (WRAP, 2013). It is perhaps this more than anything else that tells the story.

\footnotetext{
4 This was Nigel Baker's original intention.
}

Understanding food systems in their entirety includes looking at production and distribution, as well as consumer actions and behaviors. The concept of Net Yield Efficiency (NYE) developed here offers a simple way to combine yield and FLW. It contributes to the need for studies that explore structural elements in food waste and use objective measures of household waste (i.e., sorting waste) (Schanes et al., 2018). It may also serve as a starting point for further development of a measure of systemwide efficiency, for example by including nutrient losses through food processing and incorporating overconsumption. ${ }^{4}$ We have demonstrated how the community supported agriculture model, by taking into account production yield and the waste generated by supply chains and households, can be more efficient than supermarket-led systems. Attaining such efficiencies will be crucial to attaining food security in the future.

Of course, improving the efficiency of food systems is only one element of food security. Many questions remain about the CSA model, including its causal role in consumer behavior and whether it can be scaled up to meet the needs of the world's highly urbanized populations. There are also questions about whether CSAs are representative of broader society, specifically regarding their inclusion of marginalized groups. Race, income, and class-based inequalities are often (inadvertently) reproduced in local alternative food systems (Allen, 2010), such that those who are food insecure do not have the opportunity to benefit from them.

It is clear that current global food systems are in need of radical re-appraisal. The CSA model is just one of many alternative food systems, and it must be considered alongside other short, local supply chain models. We suggest that the NYE framework offers a useful tool for comparing these models. Further research that deploys the NYE framework to CSAs and similar models, both in different contexts and at larger scales, is needed. 
Journal of Agriculture, Food Systems, and Community Development

ISSN: 2152-0801 online

https:/ / www.foodsystemsjournal.org

\section{Acknowledgments}

This paper is based on the late Nigel Baker's

Masters of Science thesis. Nigel had been writing

this paper and had begun to further develop the

ideas for his Ph.D . before he passed away. His wish was for this work to be published.

The authors would like to acknowledge the support of Nigel's wife, Helen, as well as Will and Ali from Canalside CSA, both of whom assisted in Nigel's original research.

\section{References}

Allen, P. (2010). Realizing justice in local food systems. C ambridge Journal of Regions, E conomy and Society, 3(2), 295-308. https:/ / doi.org/ 10.1093/ cjres/ rsq015

Alexander, P., Brown, C. Arneth, A., Finnigan, J., Moran, D ., \& Rounsevell, M. D . A. (2017). Losses, inefficiencies and waste in the global food system. A griaultural Systems, 153, 190-200. https:/ / doi.org/ 10.1016/ j.agsy.2017.01.014.

BBC News. (2018, May 22). Teso removes 'best before' dates on some fruit and veg. (2018, 22 May). Retrieved from http:// www.bbc.co.uk/ news/ business- 44207480

Blythman, J. (2004). Shopped - the shodking power of the British Supermark ets. London: Fourth Estate (Harper Collins).

Brook Lyndhurst. (2007). F ood behaviour onsumer research: Q uantitative phase. London: Waste and Resources Action Programme [WRAP]. Retrieved from http:/ / www.wrap.org.uk/ sites/ files/ wrap/ Food\%20behaviour\%20consumer\%20research\%20quantitative\%20jun \%202007.pdf

Brook Lyndhurst. (2011). C onsumer insight: date labels and storage guidanœ. London: WRAP. Retrieved from http:/ / www.wrap.org.uk/ sites/ files/ wrap/ Technical\%20report\%20dates.pdf

Carrington, D . (2014). UK future food security threatened by complacency, MPs warn. The G uardian. Retrieved from http:/ / www.theguardian.com/ environment/ 2014/jul/ 01/ uk-food-security-threatened-complacency-mps-report

Community Supported Agriculture. (2018). W hat is C SA ? Retrieved from https:/ / communitysupportedagriculture.org.uk/ what-is-csa/

Cooley, J. P. \& Lass, D. A. (1998) Consumer benefits from community supported agriculture membership. Review of A gricultural E conomics, 20(1), 227-237. https:// doi.org/ 10.2307/ 1349547

de Ponti, T., Rijk, B., \& van Ittersum, M. (2012). The crop yield gap between organic and conventional agriculture. A gricultural Systems, 108, 1-9. https:/ / doi.org/ 10.1016/ j.agsy.2011.12.004

Food and Agriculture Organization of the United Nations (FAO). (2011). G lobal food losses and food waste- E xtent, causes and prevention. Rome: FAO. Retrieved from http:/ / www.fao.org/ docrep/ 014/ mb060e/ mb060e00.pdf

FIAN International. (2014). G $8 \mathrm{~N}$ ew A llianœ for F ood Seaurity and $\mathrm{N}$ utrition in A frica: A critical analysis from a human rights perspective. Retrieved from https:/ / www.fian.org/ fileadmin/ media/ publications 2015/2014_G8NewAlliance screen.pdf

Gustafsson, K., Jonson, G., Smith, D ., \& Sparks, L. (2009). Retailing logistics and fresh food padk aging. London: Kogan Page.

High Level Panel of Experts on Food Security and Nutrition (HLPE). (2014). F ood losses and waste in the context of sustainable food systems (A report by the High Level Panel of Experts on Food Security and Nutrition of the Committee on World Food Security, Rome). Retrieved from http:// www.fao.org/3/ a-i3901e.pdf

Ingram, J. (2011) A food systems approach to researching food security and its interactions with global environmental change. Food Security, 3(4), 417-431. https:// doi.org/ 10.1007/ s12571-011-0149-9

Institution of Mechanical Engineers. (2013, November 2). G lobal food: W aste not, want not. Retrieved from https:/ / www.imeche.org/ policy-and-press/ reports/ detail/ global-food-waste-not-want-not

Kneafsey, M., Cox, R., Holloway, L., D owler, E., Venn, L., \& Tuomainen, H. (2008). Reconnecting onsumers, producers and food: E x ploring alternatives. Oxford: Berg.

Lundqvist, J., de Fraiture, C., \& Molden, D . (2008). Saving water: From field to fork - curbing losses and wastage in the food chain (SIWI Policy Brief). Retrieved from https:/ / www.siwi.org/ publications/ saving-water-from-field-to-fork-curbinglosses-and-wastage-in-the-food-chain/

McMichael, P. (2013). F ood regimes and agrarian questions. Rugby: Practical Action. 
Ministry of D efence. (2014). Table of conversion factors for converting edible portion weights of food to 'as purchased' weights of foods: V egetables. Retrieved from http:// www.quartermaster.army.mil/jccoe/ publications/ recipes/section_a/ a006.pdf

Parfitt, J., Barthel, M., \& MacNaughton, S. (2010). Food waste within food supply chains: Q uantification and potential for change to 2050. Philosophical T ransactions of the Royal Society B, 365(1554), 3065-3081. https:/ / doi.org/ 10.1098/ rstb.2010.0126

Pinkerton, T., \& Hopkins, R. (2009). L ocal Food: H ow to make it happen in your ommunity. Devon, UK: Green Books.

Porter, S. D., Reay, D. S., Bomberg, E. \& Higgins, P. (2018). Avoidable food losses and associated production-phase greenhouse gas emissions arising from application of cosmetic standards to fresh fruit and vegetables in Europe and the UK. Journal of Cleaner Production, 201, 869-878. https:/ / doi.org/ 10.1016/ j.jclepro.2018.08.079

Ray, D ., Mueller, N., West P. C., \& Foley J. A. (2013). Yield trends are insufficient to double global crop production by 2050. PL oS O N E , 8(6), 1-8. https:// doi.org/ 10.1371/ journal.pone.0066428

Rosset, P. \& Altieri, M. (2017). A groecology: Science and politics. Rugby, UK: Practical Action.

Saltmarsh, N., Meldrum J., \& Longhurst N. (2011). The impact of community supported agriaulture. Soil Association. Retrieved from https:/ / communitysupportedagriculture.org.uk/ wp-content/ uploads/ 2015/ 03/ The-impact-of-communitysupported-agriculture.pdf

Schanes, K., D obernig, K. \& Gözet, B. (2018). Food waste matters - A systematic review of household food waste practices and their policy implications. Journal of Cleaner Production, 182, 978-991. https:// doi.org/ 10.1016/ j.jclepro.2018.02.030

Smith, P. (2013). D elivering food security without increasing pressure on land. G lobal F ood Searity, 2(1), 18-23. http:// dx.doi.org/ 10.1016/ j.gfs.2012.11.008

Stuart, T. (2009). W aste: U nowvering the global food scandal. London: Penguin Books.

Tilman, D., Balzer, C., Hill, J., \& Befort, B. L. (2011). Global food demand and the sustainable intensification of agriculture. Proceedings of the N ational A cademy of Sciences (PN A S), 108(50), 20260-20264. https:// doi.org/ 10.1073/ pnas.1116437108

World Food Summit [WFS]. (1996). Rome D eclaration on W orld F ood Security. http:/ / www.fao.org/ docrep/ 003/ w3613e/ w3613e00.htm

Waste and Resources Action Programme [WRAP]. (2009). H ousehold food and drink waste in the U K. Retrieved from http:/ / www.wrap.org.uk/ sites/ files/ wrap/ Household_food_and drink waste_in the UK_-_report.pdf

WRAP. (2011). F ruit and vegetable resource map. Retrieved from http:// www.wrap.org.uk/ sites/files/wrap/Resource_Map_Fruit and Veg_final_6 june_2011.fc479c40.10854.pdf

WRAP. (2013). H ousehold food and drink waste in the U nited Kingdom 2012. Retrieved from http:// www.wrap.org.uk/ content/ household-food-and-drink-waste-uk-2012

WRAP. (2014). H ousehold food and drink waste: A product focus. Retrieved from http:/ / www.wrap.org.uk/ content/ household-food-drink-waste-\%E2\%80\%93-product-focus 